\title{
RUEDAS DE CONVERSACIONES: A FORMAÇÃO DE PROFESSORES BRASILEIROS E BOLIVIANOS ATRAVÉS DE HISTÓRIAS E EXPERIÊNCIAS VIVIDAS NA FRONTEIRA
}

\author{
ZuILA GUIMARÃEs Cova dos SANTOS \\ Professora da UNIR \\ zuilagc@gmail.com
}

Guajará-Mirim, cidade rondoniense localizada na fronteira do Brasil com a Bolívia, é considerada cidade gêmea de Guayaramerín, pertencente ao Departamento do Beni. As populações das duas cidades possuem uma relação harmônica construída ao longo dos processos históricos de ocupação e desenvolvimento das duas cidades fronteiriças. Atualmente as cidades irmãs possuem importantes relações comerciais, políticas, turísticas, culturais e educacionais. A escola situada na fronteira internacional é um tema que estamos pesquisando e estudando nos últimos 10 anos, e parte deste caminho resultou na minha Tese de doutoramento em Geografia (Santos, 2016). O espaço de formação de professores ganha importância fundamental para estimular relações mais humanas dentro das escolas de fronteira, tendo em vista que geralmente nesses espaços há a presença do imigrante, ou seja, aquele que vem de um outro país, fala outro idioma e tem hábitos culturais diferentes. $\mathrm{O}$ projeto de iniciação científica "Ruedas de Conversaciones: interações, práticas e saberes da fronteira na formação continuada de professores da educação infantil” objetivou estimular o diálogo e o estudo coletivo de professores brasileiros e bolivianos, sujeitos fronteiriços das cidades de Guajará-Mirim e Guayaramerín, a partir de interações bilíngues (português e espanhol) e práticas interculturais. Entendemos que, ao aproximarmos estes profissionais e os acadêmicos que estão em processo de formação, instigamos novos olhares ao contexto educacional da fronteira, sensibilizamos esses sujeitos a repensarem suas práticas, seus lugares formativos e seus conhecimentos sobre a fronteira, de maneira que essa (re)

Publicado em: Dorfman, A.; Filizola, R.; Félix, J. M. (Orgs.) Ensinando Fronteiras: projetos estatais, representações sociais e interculturalidade. Porto Alegre: Editora Letra1; Editora Diadorim, 2021, p. 273-286. doi: 10.21826/9786599023460-12 
construção gere um impacto positivo no espaço escolar e estimule a verdadeira inclusão de imigrantes.

\section{Detalhes da nossa fronteira}

Guajará-Mirim, data de 1929 e é o segundo município mais antigo de Rondônia, está localizado na linha da fronteira do Brasil com a Bolívia. O rio Mamoré demarca o limite entre as cidades gêmeas de Guajará-Mirim e Guayaramerín, cidade que pertencente ao Departamento do Beni. As populações das duas cidades possuem uma relação harmônica construída ao longo dos processos históricos de ocupação e desenvolvimento das duas cidades fronteiriças. Atualmente, as cidades irmãs possuem importantes relações comerciais, políticas, turísticas, culturais e educacionais. Estas relações influenciam diretamente o fluxo de deslocamento na fronteira das duas cidades. São brasileiros e bolivianos que circulam diariamente para comprar, vender, trabalhar, estudar e investir.

A educação escolar na fronteira internacional é um tema que pesquisamos e a estudamos nos últimos anos. Ao longo desse caminho de atravessamentos, encontros e desencontros, o espaço de formação de professores ganha importância fundamental nas relações humanas construídas na escola em fronteira, tendo em vista que geralmente nesses espaços há a presença do imigrante. O projeto de iniciação científica "Ruedas de Conversaciones: interações, práticas e saberes da fronteira na formação continuada de professores da educação infantil” objetivou estimular o diálogo e o estudo coletivo em um processo de interação bilíngue (português e espanhol) e intercultural entre os professores das cidades gêmeas e acadêmicos do curso de pedagogia. Entende-se que, ao aproximarmos estes profissionais, instigamos a construção de novos olhares para contexto educacional da fronteira, sensibilizamos estes sujeitos a repensarem suas práticas, seus lugares formativos e seus conhecimentos sobre a fronteira, de maneira que essa (re)construção gere um impacto positivo no espaço escolar fronteiriço.

Nesse sentido, apresentamos nesse texto um recorte da experiência de formação de professores que atuam nas escolas da fronteira das cidades gêmeas, uma formação baseada no diálogo, nas trocas, nas reflexões e em muito aprendizado. 


\section{O rio é o coração da fronteira}

O rio não é o limite. Ele é o coração da fronteira! É o encontro, o fluxo, o ir e vir! O rio Guaporé e o rio Mamoré demarcam a linha de fronteira entre o estado de Rondônia (Brasil) e parte da Bolívia. Juntos, os dois rios fazem aproximadamente 1.400 quilômetros de extensão com linhas regulares de navegação atendendo as comunidades dos dois territórios. O rio não limita, não divide, ele é o elemento integrador das pessoas que vivem em suas margens: índios, ribeirinhos, caboclos, quilombolas, entre outros grupos que residem nessa região da Amazônia Ocidental. Comunidades que sobrevivem do que plantam, do que pescam, do que coletam. Some-se a esse contexto as áreas brasileiras protegidas sob jurisdição federal e estadual, pois a região conta com diversas Unidades de Conservação.

Neste entre-lugares da Amazônia, um espaço em constante construção social a partir dos contatos intersubjetivos e interculturais, as decisões do Estado nem sempre respondem às demandas das comunidades, ou quando respondem, nem sempre se tornam ações rápidas para combater o desemprego, à fome, as doenças, o tráfico, o desmatamento, a violência. Conforme Bhabha (1998, p. 315) entre-lugares são, "espaços de fronteira, de contato interculturais, cujas características resultam do cruzamento de referências, contestações políticas e construção de novas estratégias de sobrevivência”.

Assim sendo, as comunidades criam ações compartilhadas para tentar vencer os problemas que enfrentam, para se aproximarem e se acolherem. Surgem, então, as relações transfronteiriças, redes de apoio à produção, ao deslocamento, às práticas religiosas, à educação, à saúde, enfim, a fronteira torna-se um continuum solidário. Para Haesbaert (2013), o continuum da fronteira é a mobilidade, o fluxo, a troca.

A fronteira que trazemos para o nosso estudo tem esta característica para muitos dos moradores das cidades gêmeas; a travessia diária do limite fronteiriço está na rotina das pessoas que cruzam o rio Mamoré para trabalhar, estudar, comprar um remédio, um tecido, fazer uma visita, ir ao médico. A cidade vizinha vira extensão da nossa própria cidade, como um bairro que fica ali "depois do rio”. Nesse processo, o limite territorial não é percebido, 
despertamos para este aspecto apenas quando há algum tipo de fiscalização que exige a apresentação de documentos de identificação ou barreiras sanitárias que solicitam o cartão de vacinação. Portanto, na travessia diária o rio torna-se o coração da fronteira, ali a vida pulsa em um ir e vir constante. É a luta diária de homens e mulheres fronteiriços!

Os municípios rondonienses situados na linha de fronteira brasileira são: Guajará-Mirim, Costa Marques e Pimenteiras. Há também as comunidades situadas na linha de fronteira. São elas: Santa Cruz, 03 de Julho, Flor de Ouro, Acurizal, Ilha das Flores, Laranjeiras, Porto Rolim, Santo Antônio, Pedras Negras, Pau D'óleo, Santa Fé, Mequéns, Forte Príncipe, Surpresa, Sagarana, Pacaás Novos.

$\mathrm{Na}$ linha da fronteira boliviana temos apenas a cidade de Guayaramerín, e pequenas comunidades. São elas: Cafezal, Suzana, Matrixã, Versalles, Bellas Vistas, Taquaral e Mateguá. As cidades e comunidades brasileiras e bolivianas aqui citadas estão descritas no Plano de Desenvolvimento Integrado de Fronteira Rondônia (Rondônia, 2016), organizado pelo Núcleo Estadual para o Desenvolvimento e Integração da Faixa de Fronteira (NEIFRO).

Entretanto, em uma expedição realizada em setembro de 2017 pelo rio Mamoré, com o Grupo de Estudos Interdisciplinares das Fronteiras Amazônicas (GEIFA), vinculado à Universidade Federal de Rondônia (UNIR), foi possível conhecermos outras comunidades na linha de fronteira entre o município de Guajará-Mirim e o distrito de Surpresa. A expedição nos levou a conhecer na linha de fronteira brasileira, às margens do rio Mamoré, Deolinda, uma comunidade indígena. No lado boliviano do rio, tivemos uma grande surpresa, pois enquanto do lado brasileiro identificamos apenas uma comunidade indígena no percurso da expedição, do lado boliviano conhecemos sete comunidades ribeirinhas: Santa Anita, San Roque, Palmazola, Barranco Colorado, San Juan, Puerto Coimbra e San Lorenzo. Como descrito anteriormente, estas comunidades não foram inseridas no documento do NEIFRO e nem todas aparecem nas fotos de satélite do Google Maps.

O recorte fronteiriço onde a experiência de formação ocorreu, através do projeto de iniciação científica Ruedas de Conversaciones: interações, práticas e saberes da fronteira na formação 
continuada de professores da educação infantil, foi a fronteira das cidades gêmeas de Guajará-Mirim (Rondônia/Brasil) e Guayaramerín (Beni/Bolívia). É nesse espaço amazônico que caminhamos estudando, pesquisando, realizando práticas e contribuindo nos debates sobre a educação na fronteira. Um caminho inquieto com percursos variados, ora do lado brasileiro ora do lado boliviano. Nesse processo, entender como a educação promove integrações, inclusões, acolhidas e isolamentos, quais os projetos educacionais interculturais dos respectivos sistemas se destacam, como se dá o acolhimento ao aluno imigrante são questões que me dedico a estudar, acompanhar e contribuir.

A educação não se limita aos processos realizados dentro da escola, ela vai além, envolve outros territórios, como o político, o econômico e o cultural, por exemplo. Assim sendo, a fronteira precisa ser pensada também, a partir do olhar pedagógico. Um olhar com outros olhos! Olhos mais aguçados, capazes de perceber a dinâmica do encontro de histórias de vidas tecidas por rotas e caminhos pela fronteira, de fluxos de ideias, de práticas, de projetos, de políticas, de culturas, de leituras e tantos outros aspectos que envolvem realidades nacionais distintas entrelaçados em um espaço geográfico comum. São fatos, histórias, memórias e experiências que precisam se fazer presente no currículo escolar oportunizando vozes silenciadas da sala de aula.

\section{As Ruedas de Conversaciones}

O projeto de iniciação científica Ruedas de Conversaciones: interações, práticas e saberes da fronteira na formação continuada de professores da educação infantil, foi aprovado pela pró-Reitoria de Pesquisa da Universidade Federal de Rondônia no início do segundo semestre de 2019. Seu principal objetivo foi o de verificar o nível de interações bilíngues (português e espanhol) e se o novo idioma aprendido ganhou espaço na prática docente dos professores, após o processo de formação oferecido através das Ruedas.

Os encontros das Ruedas (vou passar a usar apenas este termo para me referir ao projeto a partir de agora), aconteciam na Escola de Municipal de Educação Infantil Bader Massud Jorge, no município de Guajará-Mirim, no lado brasileiro. Envolveu professores do sistema de 
educação municipal, acadêmicos do Curso de Pedagogia do Campus da Universidade Federal de Rondônia e professores do Departamento de Educación Distrital de Guayaramerín (Beni/Bolívia). Participaram do projeto de formação 35 professores, dentre eles 16 professores bolivianos que cruzavam a fronteira uma vez por semana para participar das Ruedas, nove acadêmicos e dez professores brasileiros.

Ao todo, foram realizados 10 encontros de duas horas. Para cada encontro, eram programadas atividades conforme a organização dos eixos de estudos planejados no projeto: o eixo Linguagem (jogos, música, literatura, poemas em português e espanhol) trabalhado em todos os encontros, o eixo Ludicidade (tendo em vista que eram professores que atuavam na educação infantil) e o eixo História e Geografia (que apresentou um pouco da história da formação das cidades gêmeas a partir dos textos de cada nação).

A propósito, vale destacar que envolver professores de nacionalidades diferentes em um mesmo espaço de diálogo e formação não é uma prática comum nas fronteiras internacionais do norte do nosso país e nem mesmo em nossa fronteira porque poucos gestores da educação local conseguem ter olhar diferenciado para a fronteira - como já apontado anteriormente, "é preciso olhar com outros olhos". Estimular a interação de professores de nacionalidades diferentes, que estão em atividade diária, dá trabalho! É preciso organizar horários, prever gastos com deslocamentos, organizar espaço para os encontros, entre outras questões de suporte: como água, lanche, café, materiais didáticos e recursos tecnológicos.

Mas, apesar das dificuldades que envolvem os sistemas de ensino da nossa região, foi possível firmar parcerias com diretores de duas escolas brasileiras, os participantes bolivianos assumiram seus gastos para se deslocarem de barco da Bolívia para o Brasil, conseguimos o espaço e equipamentos na escola que sediou os encontros. No Brasil, quem tinha carro ou moto oferecia carona para quem não tinha, os lanches servidos nos encontros foram compartilhados, a cada encontro um grupo se responsabilizava em levar alguma coisa para partilhar. O momento do lanche era muito rico, não pela quantidade, mas pela diversidade dos alimentos bolivianos e brasileiros, com diferentes texturas e sabores. Era uma grande ceia intercultural. 
Essa rede solidária que foi construída, para que as Ruedas fossem realizadas, pode ser aqui analisada a partir do direito ao atravessamento, um atravessar que não se limita a fronteira geográfica, mas envolve também a travessia das fronteiras institucionais do Estado, como escolas e Secretarias de Educação. Estas instituições em sua maioria estão fechadas em um mundo burocratizado, engessadas em políticas de governo fragmentadas, instituições que pouco escutam as demandas que ecoam da sociedade, não há uma preocupação com aqueles que se deslocam de países fronteiriços para estudar, trabalhar, viver. Por isso, "o direito à educação e à mobilidade ressoam como um clamor dos novos tempos, que exige ser escutado porque se torna realidade no exercício cotidiano de nossas vidas e de novas formas de habitar o mundo" (Corsini, 2012, p.35).

\section{A metodologia das Ruedas de Conversaciones}

Para envolver o grupo participante que, em sua maioria, chegava cansado da rotina de um dia de trabalho escolar, optamos por uma metodologia de trabalho que fosse estimulante e oportunizasse as interações bilíngues. Assim, nos orientamos pela experiência de formação humana das Rodas e Registro (Warschauer, 1993), uma metodologia de formação estudada pela doutora em educação Cecília Warschauer.

Nas rodas, a formação humana acontece a partir das histórias e experiências, num processo de desconstrução e reconstrução, onde reagimos aos movimentos vindos de "fora" e de "dentro" - nossas emoções, nossas reflexões, a interpretação e os sentidos que lhes atribuímos. Nessa perspectiva, as Ruedas fomentaram o diálogo sobre a educação na fronteira, abrindo espaço para reflexões individuais sobre o fazer pedagógico e promovendo reflexões sobre as representações da fronteira. O diálogo bilíngue iniciou de forma tímida, mas foi sendo ampliado à medida em que as práticas de formação promoviam novas organizações do grupo, agregando professores brasileiros como professores bolivianos. Nessa relação dialógica surgiram as diferenças e os modos de viver e conviver em que a diversidade cultural passou a ser trabalhada com equidade e a história do outro a ser respeitada, numa dinâmica que pode ser expressa através das palavras de Imbernón: 
A formação assume um papel que vai além do ensino que pretende uma mera atualização científica, pedagógica e didática, e se transforma em possibilidade de criar espaço de participação, reflexão e formação para que as pessoas aprendam e se adaptem para poder conviver com a mudança e a incerteza. (Imbernón, 2006, p.18).

As Ruedas buscaram responder necessidades e lacunas presentes na formação de professores brasileiros que atuam na educação infantil e primeiros anos do ensino fundamental. São nesses níveis que a presença do aluno imigrante boliviano ou brasileiros descendentes de pais bolivianos, é maior. Esta situação requer atenção e dedicação dos professores que atuam diretamente com essas crianças, pois a maioria chega à escola com pouco, ou nenhum conhecimento da língua portuguesa.

Por outro lado, a maioria dos professores apesar de morarem na fronteira com um país de língua espanhola, no caso a Bolívia, não dominam o espanhol. Assim passam a ter problemas no processo de interação com o aluno imigrante, não conseguem escutá-lo, acolhê-lo e ensiná-lo. Geralmente esses alunos ficam recolhidos a um canto da sala, silenciados por um currículo escolar e uma prática pedagógica que não contribui para incluí-lo verdadeiramente nas práticas escolares. E ainda, na educação infantil, como não conseguem ser entendidos, choram muito, quebrando a harmonia da sala. O professor estressado e cansado com a dificuldade de comunicação vai negligenciando sua interação com o aluno imigrante, e este vai se isolando, até chegar ao ponto de não ter mais interesse em ir para escola. Consequentemente a evasão do aluno imigrante acontece e, na maioria das vezes, não ganha atenção dentro da escola. E, de forma velada, os problemas que geram a falta de acolhimento aos alunos imigrantes vão sendo esquecidos e não entram nas pautas de discussão das escolas da fronteira.

Do lado boliviano a situação é muito parecida, o imigrante brasileiro tem fácil acesso à rede de ensino boliviano, não há tanta burocracia como nas escolas brasileiras. Mas, a questão do idioma também é uma grande barreira para a verdadeira inclusão do alu- 
no brasileiro. Destaca-se que o número de imigrantes brasileiros que estudam nas escolas bolivianas da fronteira é bem menor. No entanto há um movimento, mesmo que tímido, por parte de educadores de Guayaramerín (Beni/Bol) para incluir a Língua Portuguesa no currículo escolar.

Atualmente, não temos, a nível nacional, políticas que orientem e apoiem projetos de integração educacional para as fronteiras internacionais brasileiras. Infelizmente, o Programa Escolas Interculturais de Fronteira (PEIF) que orientava e apoiava às práticas educacionais de integração fronteiriça foi suspenso ${ }^{1}$. No entanto, as fronteiras e seus sujeitos criam dinâmicas de integrações próprias que ora se constituem em acordos políticos e econômicos, ora se constitui em projetos culturais, turísticos, ora em ações solidárias, e também em práticas educacionais de intercâmbios entre os alunos dos países fronteiriços. Tudo depende das relações, afinidades, interesses e necessidades entre às populações limítrofes.

Ao refletirmos sobre a experiência vivida através dos encontros das Ruedas de Conversaciones percebemos que além de estimular os conhecimentos linguísticos, pedagógicos e históricos da fronteira, estimulamos a construção de um estado de alteridade a partir dos relatos de angústia e sofrimento que muitos alunos imigrantes passam dentro das escolas brasileiras. Portanto, acreditamos que o professor, ao retornar para sua sala de aula, poderá ousar fazer a diferença, dando voz aos que se encontram silenciados.

\section{A experiência de formação tecida a várias mãos}

O projeto de formação envolveu 26 professores (brasileiros e bolivianos) e nove acadêmicos de Pedagogia do Campus de Guajará-Mirim da Universidade Federal de Rondônia, totalizando 35 participantes. No início do curso, os participantes preencheram um questionário diagnóstico, nos permitindo conhecer um pouco da vida

1 O PEIF passou a fazer parte das políticas da Educação Integral e de acordo com os dados publicados no portal do MEC, o objetivo do programa foi o de promover a integração regional por meio da educação intercultural e a formação integral das crianças e dos jovens nas regiões de fronteira do Brasil com outros países, aderiram ao programa 16 escolas, sendo três na região do Mato Grosso do Sul, duas em Roraima e 11 escolas na região sul (BRASIL, 2012). 
profissional de cada um e, também conhecer o nível de conhecimento do idioma do país vizinho, no caso o português e o espanhol.

Do total de professores participantes apenas um era do sexo masculino. A maioria dos professores atuava em turmas de educação infantil, com um tempo entre 10 a 30 anos de profissão nos sistemas públicos de ensino das respectivas cidades da fronteira, ou seja, Guajará-Mirim (Brasil) e Guayaramerin (Bolívia). Contudo, apesar de residirem há um bom tempo na fronteira, a maioria deles não fala $\mathrm{e}$ nem escreve no idioma do país vizinho, mas conseguem entender. Esta situação confirma, como apontado anteriormente, a dificuldade que os professores possuem para interagirem com as crianças.

A qualificação profissional é muito importante para que possamos ultrapassar a principal barreira do acolhimento escolar, a Língua. A relação professor-aluno é mediada por processos comunicativos que envolvem o ensino e a aprendizagem. Portanto, é essencial garantir aos professores que atuam nas escolas de fronteira, uma formação que desenvolva o conhecimento da língua espanhola, mas também aprofunde a discussão sobre direitos e ações humanitários para imigrantes e refugiados, sobre práticas bilíngues, plurilíngues, sobre práticas de ensino interculturais e multiculturais. E ainda, a escola precisa oferecer também a esses alunos imigrantes um atendimento psicossocial, tendo em vista que muitas dessas crianças chegam ao país, com sequelas emocionais do processo migratório. Acrescenta-se, também, que as ações de inclusão não podem ficar somente sob a responsabilidade do professor da sala, mas devem ser um compromisso coletivo da comunidade escolar, firmado no Projeto Político Pedagógico (PPP).

Nas entrevistas realizadas ao final do período de formação das Ruedas de Conversaciones identificamos, através das repostas dos participantes, quais os novos conhecimentos adquiridos e se eles conseguiram ampliar as interações pessoais para além do espaço de formação, ou seja, uma rede transfronteiriça.

Os resultados apontaram que $80 \%$ dos participantes ampliaram o conhecimento no idioma do país vizinho (espanhol e português). Descobriram que apesar dos idiomas terem palavras com sons semelhantes e parecer fácil a aprendizagem, quando partimos para a escrita percebemos que não é tão fácil assim. O conhecimen- 
to linguístico adquirido por eles foi comprovado ao longo do curso, pois estrategicamente organizávamos grupos de trabalhos mistos, com professores brasileiros e professores bolivianos, e para responder as atividades ou realizarem alguma ação era sempre necessário muita conversa entre eles. Na sala, era possível ouvir o diálogo bilíngue, ora com pergunta em espanhol e resposta em português, ora ao contrário à ordem anterior e, muitas vezes, através de uma estrutura bilíngue presente em uma mesma frase, como por exemplo "Yo não sei hablar muito bem o português, mas me encanta conocer una nueva língua" ${ }^{2}$. Este exemplo ganha destaque porque a professora que fez esse comentário, ao preencher o questionário aplicado no início do curso, afirmou não saber falar em português, mas ao final do curso já utilizava algumas palavras em português.

Uma outra estratégia que utilizamos para estimular a aquisição do novo idioma foi solicitar que os professores utilizassem as músicas, brincadeiras e histórias que aprenderam em português e espanhol, nas salas de aula com os alunos que eles ensinavam. Depois, conforme se sentiam seguros solicitávamos que compartilhassem pequenos vídeos das práticas realizadas, no grupo de Whatsapp que criamos para estimular as conversas bilíngues. Os vídeos apresentaram práticas lúdicas com muita música e historinhas. Foi muito gratificante ver crianças bolivianas cantando e representando as músicas infantis brasileiras e as crianças brasileiras cantando em espanhol as músicas infantis tradicionais das comunidades bolivianas. A experiência demonstrou que é possível ousar e fazer a diferença para aproximar as culturas da fronteira.

Ao trabalharmos a história e a geografia da fronteira das cidades gêmeas, apresentando textos e bibliografias dos dois países, foi possível perceber o desconhecimento deles sobre a história e a geografia do país vizinho. Ficando claro portanto, que ao trabalharem esse assunto nos anos iniciais, etapa onde deve ser incluída a história e a geografia local, a maioria dos professores brasileiros por exemplo, se limita a trabalhar conteúdos apenas da cidade de Guajará-Mirim, do estado de Rondônia e do Brasil. Não abordam a história e geografia da cidade boliviana vizinha, esquecem que as duas cida-

2 Professora boliviana, atua a 20 anos na educação de Guayaramerín (Beni/Bol). - O registro da frase foi feito no caderno de campo da autora. 
des têm uma história comum, que se desenvolveram mutuamente a partir de uma interdependência econômica, política e social.

As populações fronteiriças também se entrelaçam devido aos casamentos entre brasileiros e bolivianos. No município de Guajará-Mirim, há muitos brasileiros descendentes de famílias bolivianas e estes geralmente podem ser identificados pelos sobrenomes em espanhol, em aimara ou em quéchua.

É importante, portanto, ultrapassar os limites impostos pelo território do curricular escolar e garantir ampliações e projeções dos conhecimentos específicos da região onde a escola de fronteira se encontra. Ao conhecer a história do outro começamos a respeitá-lo a entendê-lo e isso é importante para vencermos comportamentos preconceituosos e representações ultrapassadas sobre as migrações.

Para concluir, destaco que as interações pessoais construídas inicialmente dentro das Ruedas de Conversaciones foram sendo fortificadas pelos participantes e se estenderam para fora das Ruedas. As conversas passaram a acontecer com mais frequência entre algumas pessoas, que foram ficando mais próximas e as conversas que trocavam não se restringiam aos estudos ou a prática docente, mas passaram a envolver aspectos familiares, rotinas do lar, receitas, compra de produtos e outros, como podemos ver no relato abaixo:

[...] eu acho que minha interação lá com os colegas bolivianos ultrapassou os limites do nosso curso das Ruedas de Conversaciones, porque eu conversei bastante sobre tudo, a gente estava sempre se envolvendo perguntando quem era casado quem não era, quem tinha filho, o que o filho fazia, como é a vida. Eu fiz amizade com a Danitza e ai agente estava sempre conversando inclusive eu fazia até encomendas com ela, naquele tempo lá estava naquela guerra, manifestação contra a eleição do Evo, os portos fecharam e ninguém passava. Mas eles conseguiram passar para estudar e ela trouxe a encomenda. (Professora brasileira) 
A professora citada é Danitsa Silenea Arteaga, ela tem 38 anos é professora da Educación primaria comunitária da escola 9 de Abril $/ 3^{\circ}$ ano. Participou do projeto de formação para trocar experiências com professores brasileiros. O recorte da entrevista da professora brasileira demonstra que a rede de interação que era estimulada através dos encontros de estudo se consolidou e para alguns participantes essa rede se projetou para fora do espaço de formação, atravessou os limites fronteiriços e se firmou a partir de novas amizades.

Finalizo, com a certeza que nas escolas de fronteira, em especial as fronteiras do norte tão distante dos centros de decisões do nosso país, tem sempre alguém ou grupo trabalhando para garantir que imigrantes sejam acolhidos. Que as práticas exitosas dessas comunidades escolares sejam reconhecidas, estimuladas e apoiadas por seus sistemas gestores. Portanto, é preciso reconhecer as demandas da imigração nas escolas e intervir com políticas de estado construídas a partir das vozes das fronteiras.

\section{Referencias}

BHABHA. Homi K. O local da cultura. Belo Horizonte: ED. UFMG, 1998.

BRASIL. Programa Escola Interculturais de Fronteira - PEIF. Brasília: MEC, 2012.

CORSINI, Leonora. Fronteiras, atravessamentos e deslocamentos: desenhando novas cidadanias. In: MACIEL, Tania Barros; NETO; Maria Inácia D’Ávila; ANDRADE, Regina Gloria (Orgs). Fronteiras e diversidades culturais no século XXI. Rio de Janeiro: Mauad X -FAPERJ, 2012.

HAESBAERT, Rogério. O território e a nova des-territorialização do estado. In: DIAS, Leila Christina; FERRARI, Maristela. (Orgs.) Territorialidades humanas e redes sociais. $2^{\mathrm{a}}$ ed. Florianópolis: Insular,2013, p. 19-37.

IMBERNÓN, Francisco. Formação docente e profissional: forma-se para mudança e a incerteza. $6^{\mathrm{a}}$ ed. São Paulo: Cortez, 2006.

RONDÔNIA, Plano de desenvolvimento integrado de fronteira Rondônia. Governo do Estado de Rondônia. Porto Velho: GER, 2016.

SANTOS, Zuila Guimarães Cova dos Santos. Interações e representações sociais: um estudo do espaço escolar na fronteira do Bra- 
sil com a Bolívia. Universidade Federal do Paraná - UFPR. Tese de Doutorado em Geografia, Programa de Pós-Graduação em Geografia, Curitiba (PR), 2016. Link para acesso: https://acervodigital.ufpr. $\mathrm{br} /$ bitstream/handle/1884/48869/R\%20-\%20T\%20\%20ZUILA\%20 GUIMARAES\%20COVA\%20DOS\%20SANTOS.pdf;jsessionid=41E977FE053A5F1022AC6B7DCD779806? sequence $=1$. WARSCHAUER, Cecília. A roda e o registro: uma parceria entre professores, alunos e conhecimento. $1^{\mathrm{a}}$ ed. Rio de Janeiro: Paz \& Terra, 1993. 